\title{
Daphnia body size and population dynamics under predation by invertebrate and fish predators in Lago Maggiore: an approach based on contribution analysis
}

\author{
Marina MANCA ${ }^{1 * *}$, Jacobus VIJVERBERG ${ }^{2)}$, Leonard V. POLISHCHUK ${ }^{3)} \&$ Dmitry A. VORONOV $^{4)}$ \\ ${ }^{1)}$ CNR Institute for the Study of Ecosystems, Largo Tonolli 52, 28922 Verbania, Italy. \\ ${ }^{2}$ Netherlands Institute of Ecology (NIOO-KNAW), Centre for Limnology, Rijksstraatweg 6, 3631 AC Nieuwersluis, The Netherlands \\ ${ }^{3)}$ Department of General Ecology, Biological Faculty, M. V. Lomonosov Moscow State University, Moscow 119992, Russia \\ 4)Institute for Information Transmission Problems RAS, Bolshoi Karetny pereulok 19, Moscow 127994, Russia \\ *e-mail corresponding author: m.manca@ise.cnr.it
}

\begin{abstract}
Predation on Daphnia is size-specific: while zooplanktivorous fish select large, ovigerous females, carrying larger clutches, predation by invertebrates, particularly Cladocera, is generally regarded as acting mainly on young, small, non-ovigerous females. The two types of predators therefore produce different effects on the population of their prey: fish predation results in decreases in Daphnia fecundity, proportion of adults, and maximum body size, while predation by the invertebrate predators leads to decreases in the number and proportion of juvenile Daphnia. We investigated the effect of predation by three predators (one vertebrate, two invertebrates) on Daphnia. The study combines contribution analysis of Daphnia birth rate dynamics, with a body-size-oriented analysis of both predator and prey populations. Contribution analysis showed that during April-May, when Bythotrephes densities were low, changes in Daphnia birth rate were due to both changes in fecundity $(\mathrm{ConF})$ and in the proportion of adults (ConA), with ConA being much larger (by absolute value) than ConF; such a pattern is expected under fish predation. Whereas during mid May to June, when Bythotrephes densities were high, changes in Daphnia birth rate were again mainly due to both ConF and ConA, but now the difference between these contributions was less pronounced. Although Bythotrephes predation produced similar effects on Daphnia population dynamics as fish predation, affecting both fecundity and the proportion of adults, it can be distinguished in two ways from fish predation. Firstly, the ConF-ConA pattern is more uniform under invertebrate predation than under fish predation and secondly, the mean body size of Daphnia increased continuously whereas the mean size of ovigerous females remained approximately constant except for the last 3 weeks of June, indicating a high mortality of juveniles during the whole period and an increased mortality of young females with eggs during the last 3 weeks. We conclude that both zooplanktivorous fish and invertebrate predators affect population dynamics of Daphnia in Lago Maggiore. However, the invertebrate predator Bythotrephes has the largest impact on Daphnia dynamics in June, both because of its high densities and its relatively large size at that time. Predation pressure exerted by Bythotrephes is high enough to reduce the Daphnia densities at the end of June to low values.
\end{abstract}

Key words: Bythotrephes, Leptodora, Coregonus, size-selective predation

\section{INTRODUCTION}

Predation on Daphnia is size-specific, while zooplanktivorous fish positively select large, ovigerous females carrying larger clutches, predation by invertebrate predators generally acts on small, young, non-ovigerous females (Zaret 1980). In the pelagic zone of Lago Maggiore, a deep subalpine lake in Northern Italy and the second largest lake in Italy (surface area $=212.2$ $\mathrm{km}^{2}, \mathrm{Z}_{\max }=370 \mathrm{~m}$ ) two cladoceran invertebrate predators (i.e. Bythotrephes longimanus and Leptodora kindtii) and zooplanktivorous fish (coregonid spp.) play a dominant role as feeders on zooplankton (de Bernardi et al. 1987; Manca et al. 2000; Volta 2000).

Bythotrephes longimanus (Cladocera: Onychopoda) is a native invertebrate predator in the open water of Lago Maggiore. Before (pre-1960) and during (1960-1978) cultural eutrophication $B$. longimanus densities were

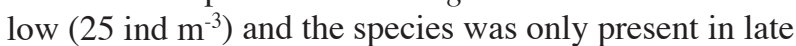
summer and early autumn (Manca et al. 1992; Manca \&
Ruggiu 1998). Following re-oligotrophication a 10 -fold increase in densities from the 1980s to the early 2000s was accompanied by a 3-month earlier onset of population growth and a nearly 6-month increase in the duration of its occurrence in the water column (Manca et al. 2007).

Bythotrephes is a cruising predator (Gerritsen \& Strickler 1977) that swims continuously throughout the water column and strikes at zooplankton prey as they pass close by. It detects prey by mechanoreceptors located on the first antennules, mandible, labrum, maxillary process and thoracic limbs (Martin \& Cash-Clarck 1995 ) or visually by its large medial compound eye. Unlike Leptodora, Bythotrephes does not have a feeding basket for prey capture. Instead it grasps a prey item with its long feeding appendages and shreds its prey, ingesting only soft parts (Schulz \& Yurista 1999). Because it is not restricted by the capacity of its feeding basket, large Bythotrephes are probably able to feed successfully on larger prey items. 
There is an increasing amount of field observations from N. America, where the exotic Bytotrephes has invaded lakes, showing that this predator often has a serious impact on the microcrustacean zooplankton communities. These results show further that in general cladocerans are more vulnerable to Bythotrephes predation than copepods and that smaller and intermediate sized cladocerans are more vulnerable than large cladocerans (Yan et al. 2001, 2002). Average species richness was $30 \%$ higher in the reference as in the invaded lakes (Boudreau \& Yan 2003). Total zooplankton biomass was significantly lower too in the invaded lakes, mainly because of lower abundances of all common epilimnetic cladoceran species. In a more recent but similar field study in North American lakes, Strecker et al. (2006) showed that Bythotrephes significantly reduced cladoceran species richness, diversity and abundance. The larger species Daphnia longiremis and Daphnia mendotae also had lower abundances in invaded lakes as compared to reference lakes, suggesting that small body size alone does not provide refuge from Bythotrephes predation. This is corroborated by the results of Barbiero \& Tuchman (2004) who showed that in lakes Michigan, Huron and Erie, Daphnia retrocurva and Daphnia pulicaria declined dramatically after the introduction of Bythotrephes.

Since Bythotrephes, unlike Leptodora, does not have a feeding basket for catching its prey, prey size cannot be estimated from the dimensions of the feeding basket as was done previously for Leptodora (Manca \& Comoli 1995; Branstrator 1998) and, therefore, vulnerability of prey species and prey size classes has to be inferred from experiments. Bythotrephes is difficult to keep under laboratory conditions, therefore published information about selective feeding is scarce, to our best knowledge only two experimental studies exist which report contrasting results. Schulz \& Yurista (1999) concluded that Bythotrephes is selecting medium sized (1.4$1.6 \mathrm{~mm}$ ) daphnids (one experiment) and/or daphnids larger than $2.0 \mathrm{~mm}$ (another experiment), whereas Vanderploeg et al. (1993) concluded on basis of their predation experiment that mainly cladocerans in the size range of ca. 0.5-0.9 $\mathrm{mm}$ were selected as food items.

Leptodora is a cruising predator, and employs strike tactics to capture prey. The prey location space for Leptodora is limited to a small forward-directed area and direct contact with the prey is required before an attack is initiated (Browman et al. 1989). Leptodora tears the cladocerans apart, the wider the ventral carapace gape of the prey the easier for Leptodora to tear it apart (Browman et al. 1989). An important limiting factor for prey capture success is the size of the feeding basket, a structure formed by thoracic appendages enabling Leptodora to catch and handle prey for ingestion (Manca \& Comoli 1995; Branstrator 1998).

Leptodora feeds mainly on small-bodied cladocerans and avoids copepodite copepods (e.g. Lunte \& Luecke
1990; Herzig 1994). Although relatively large, Diaphanosoma and Daphnia spp. are eaten too, from a newborn size ( $c a 0.5 \mathrm{~mm}$ ) until a maximum size of ca. $1.0 \mathrm{~mm}$ (Browman et al. 1989; Herzig 1995). Only very few Leptodora consume Daphnia $>1.0 \mathrm{~mm}$ and these Leptodora were always $>11.0 \mathrm{~mm}$ (Branstrator \& Lehman 1991). Copepod nauplii and rotifers are eaten by small juvenile Leptodora (i.e. $<5 \mathrm{~mm}$ ), but contribute in terms of biomass generally little to the Leptodora diet as a whole (Arndt et al. 1993).

The invertebrate (Bythotrephes, Leptodora) and vertebrate (coregonid spp.) types of predators produce different effects on the populations of their Daphnia prey: fish predation results in decreased Daphnia fecundity, decreased proportion of adults, and a reduction of adult body size, while predation by the invertebrate predators leads to a decrease in the proportion of young Daphnia and, therefore, in an increase in the proportion of adults (Gliwicz \& Pijanovska 1989; Polishchuk 1995).

Here we present the results of a field study of predation by two types of predators (one vertebrate, two invertebrates) on Daphnia, which was aimed at investigating the predator's, rather than the prey's, size-specific response. The study combines contribution analysis of Daphnia birth rate dynamics (Polishchuk 1995), with a body-size-oriented analysis of both predator and prey populations.

\section{MATERIAL AND METHODS}

\subsection{Sampling of zooplankton}

Zooplankton samples were collected in May-June 2001 at weekly intervals at a station corresponding to the maximum lake depth. They represented the content of at least $1000 \mathrm{~L}$ of lake water filtered through a 126 $\mu \mathrm{m}$ nylon net mounted on a Clarke-Bumpus plankton sampler, which was towed along a sinusoidal trajectory within the upper $50 \mathrm{~m}$, the water layer where cladocerans are distributed. Daphnia and Bythotrephes size estimates were the result of measurements of body length (from the apex of the head to the base of the carapace spine) of 200 individual Daphnia per sample and all Bythotrephes individuals found in each sample.

\subsection{Contribution analysis and population dynamics}

Contribution analysis (Caswell 1989; Polishchuk 1995, 1999; Polishchuk \& Vijverberg 2005) was used to investigate the relative importance of different environmental effects to changes in Daphnia birth rate. The idea behind the analysis is to assess the role of major environmental factors such as food, predation, and temperature in terms of corresponding population parameters.

In Daphnia, temperature mainly acts on the developmental time of eggs, while food conditions affect fecundity (number of eggs or embryos per adult female where being adult is normally determined on the basis of body 
size). Fish predation, being directed against larger adult females carrying larger clutches, influences both fecundity and the proportion of adults. Predation by invertebrates is thought to be mainly directed against juveniles, and therefore is related to the increase in the proportion of adults. Also, if invertebrate predators take off some of the smaller adults with few or no eggs, they will affect fecundity too, though probably to a lesser extent than fish. We expect therefore that fish, as compared with invertebrate predators, will produce a more pronounced and potentially less uniform (with more room for variation) effect on fecundity and the proportion of adults of their prey.

The per capita birth rate $(b)$ of Daphnia is calculated according to equation:

$$
b=V \ln (1+F A)
$$

where: $V$ is egg developmental rate $\left(\right.$ day $\left.^{-1}\right)$, the reciprocal of egg developmental time, obtained from mean water temperature of the sampled water layer; $F(F=E$ / $\mathrm{Nad}$ ) is fecundity, the ratio of eggs numbers to adult females numbers, irrespective of whether those females carry eggs or not; $A(A=N a d / N)$ is the proportion of adult females to the total number of individuals in the population. The product $F A$ is equal to $E / N$; therefore, by substituting $F A$ in equation (1) we obtain:

$$
b=V \ln (1+E / N)
$$

which represents the Edmondson and Paloheimo equations for birth rate estimation (Edmondson 1968; Paloheimo 1974). The rate of population increase $(r)$ was estimated by:

$$
r=\left(\ln N t_{2}-\ln N t_{1}\right) /\left(t_{2}-t_{1}\right)
$$

where $N t_{1}$ and $N t_{2}$ are the number of individuals in the population at times $t_{1}$ and $t_{2}$..
Death rates $(d)$ are estimated by:

$$
d=b-r
$$

Starting from equation (1) contributions of $F, A$ and $V$ (ConF, ConA, ConV) to changes in $b$ can be expressed as partial derivatives with respect to the corresponding parameters times changes in those parameters:

$$
\begin{gathered}
d b / d t=[V A /(1+F A)](d F / d t)+[V F /(1+F A)](d A / d t)+ \\
+[\ln (1+F A)](d V / d t)
\end{gathered}
$$

where: $\operatorname{Con} F=[V A /(1+F A)](d F / d t)$,

ConA $=[V F /(1+F A)](d A / d t)$,

and $\operatorname{Con} V=[\ln (1+F A)](d V / d t)$.

However, the sum of the contributions determined in this way is not exactly equal to $\mathrm{d} b / \mathrm{d} t$ (Polishchuk 1995). Hence, one of us (D.A.V.) proposed taking integral of the contributions over time, with the result that the sum of contributions is precisely equal to the change in $b$ over sampling interval, $\Delta b$. Such integrals can be calculated numerically. This method is used in the present study. Provided that changes in temperature are not large, ConV is relatively small, and changes in Daphnia birth rate can be analysed in terms of ConF (food conditions) or both ConA and ConF (predation), with the ConA-ConF pattern being less uniform (i.e. the difference between ConA and ConF being more pronounced) under fish predation than under invertebrate predation.

\section{RESULTS}

Daphnia population density increased during April and May (Fig. 1); the subsequent decline corresponded to an increase in Bythotrephes abundance. Leptodora, although appearing in late May, started its numerical

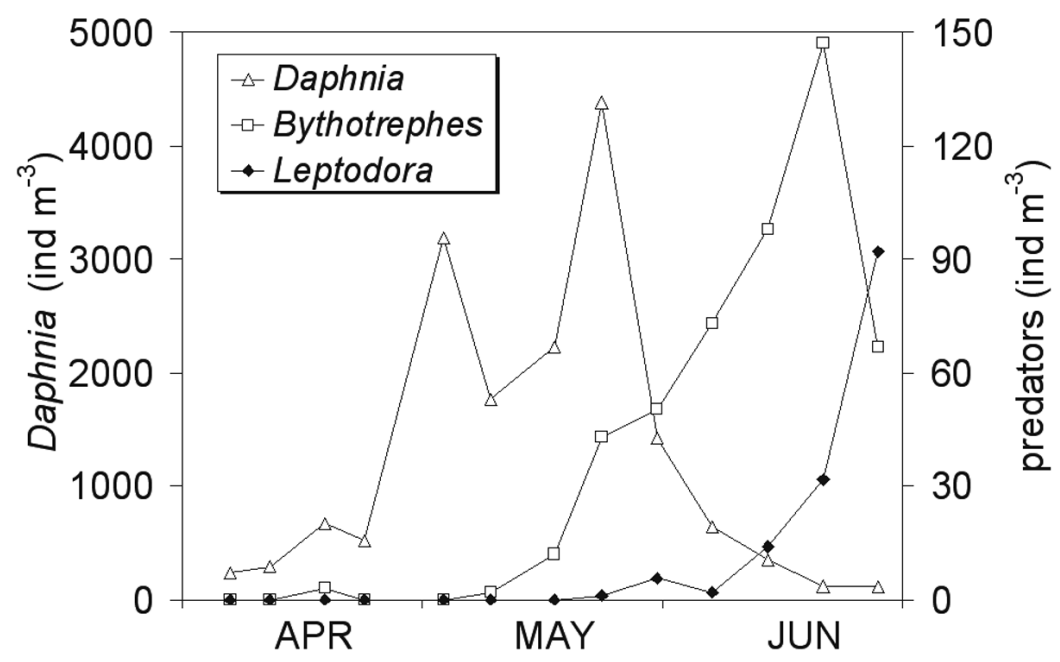

Fig. 1. Seasonal dynamics of Daphnia hyalina-galeata, Bythotrephes longimanus and Leptodora kindtii in Lago Maggiore, 2001. 


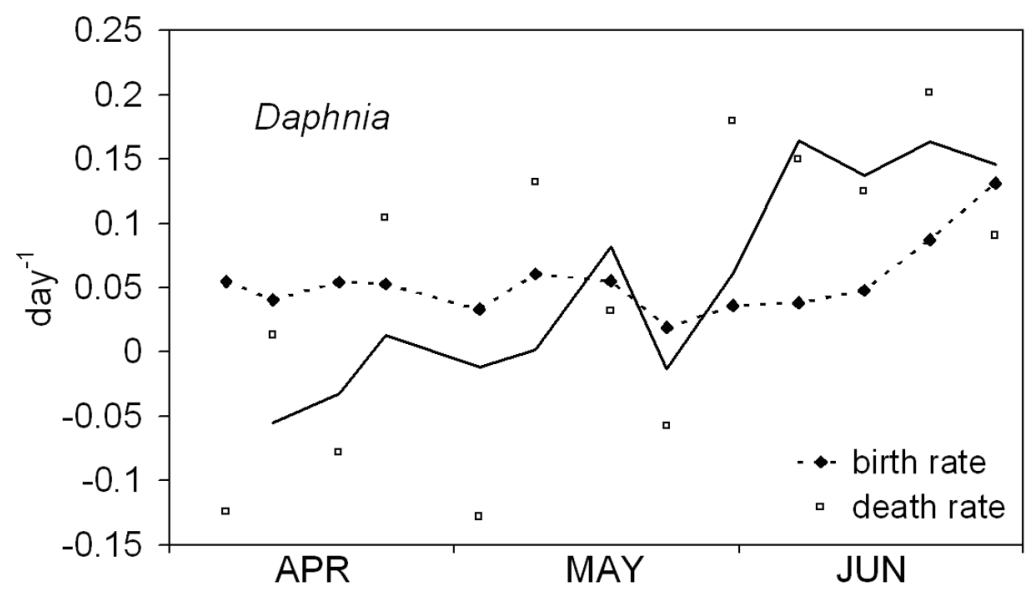

Fig. 2. Seasonal changes in per capita death rates $\left(d\right.$, day $\left.^{-1}\right)$ and birth rates $\left(b\right.$, day $\left.{ }^{-1}\right)$ of Daphnia hyalina-galeata in Lago Maggiore, 2001. Trend line of death rates is based on moving averages.

increase in June, when Daphnia numbers were already low.

During April to mid May the per capita birth rate $(b)$ of Daphnia was approximately 0.05 day $^{-1}$ and showed only little variation over time. At the end of May it reached its lowest value $\left(0.02\right.$ day $\left.^{-1}\right)$ after which it steadily increased to values of $0.08-0.13$ day $^{-1}$ during the second half of June (Fig. 2). The per capita death rate $(d)$ showed much more variation in time. Part of it was due to sampling errors, because population densities were estimated on one station only. To reduce variation we calculated the moving average of the death rate over time (Fig. 2). We can distinguish two main phases in the seasonal death rate $(d)$ pattern of the Daphnia population. The first phase, in April to mid May when the death rates slowly increased but were still very low, was concomitant with low Bythotrephes and Leptodora densities and a sharp increase of Daphnia densities during early May. The second phase started during the last week of May with a strong increase in the death rate, which reached high values in early June and remained high during that whole month. This phase was concomitant with sharp increasing Bytotrephes densities (until mid June) and steady increasing Leptodora densities from mid June onwards. This high death rate was associated with a sharp decrease in Daphnia densities (Fig. 1).

The body size of the Daphnia ovigerous females decreased during April and early May, then remained more or less constant till mid June, and increased in size in the second half of June. The mean clutch size started high in April-mid May, then decreased during the second half of May and remained low during early June and then from mid June onwards started to increase again until the end of June (Fig. 3). The mean size at maturity (MSAM) varied from $1.6 \mathrm{~mm}$ in early April to $1.85 \mathrm{~mm}$ in the second half of June.

Not only was Bythotrephes becoming more abundant in May-June, but also the maximum body size it attained was increasing, reaching its maximum value at the end of June (Fig. 4). Daphnia mean size decreased somewhat during April, but then from early May onwards increased steadily during May and June; largest body sizes were reached during the second half of June. From early May onwards increase in body size of Daphnia and Bythotrephes occurred approximately with the same rate.

Contribution analysis showed that during April-mid May, when Bythotrephes densities were low, changes in Daphnia birth rate were due to both ConF and ConA, with ConA being much larger (by absolute value) than ConF (Fig. 5a). During mid May to June changes in Daphnia birth rate were again mainly due to both $C o n F$ and $\operatorname{Con} A$, but now the difference between ConA and ConF was less pronounced (Fig. 5b). During late June, when Leptodora population density increased and Daphnia densities fell to low values, changes in birth rate were mainly related to $\operatorname{ConA}$ (Fig. 5c).

\section{DISCUSSION}

Predation on Daphnia by fish or invertebrates is sizeselective; while fish prey on larger ovigerous females carrying large clutches, invertebrates are generally thought to remove only small, immature females, though removal of some of the smaller adults with few eggs is probably also possible. The two types of predation produce different patterns of the population dynamics of the prey, which can be identified by an analysis of Daphnia birth rate dynamics and body size. When fish predation prevails, changes in Daphnia birth rate are determined by both changes in the proportion of adults $(C o n A)$ and in fecundity $(C o n F)$, with $\operatorname{Con} A$ being much larger (by absolute value) than $C o n F$ becau- 


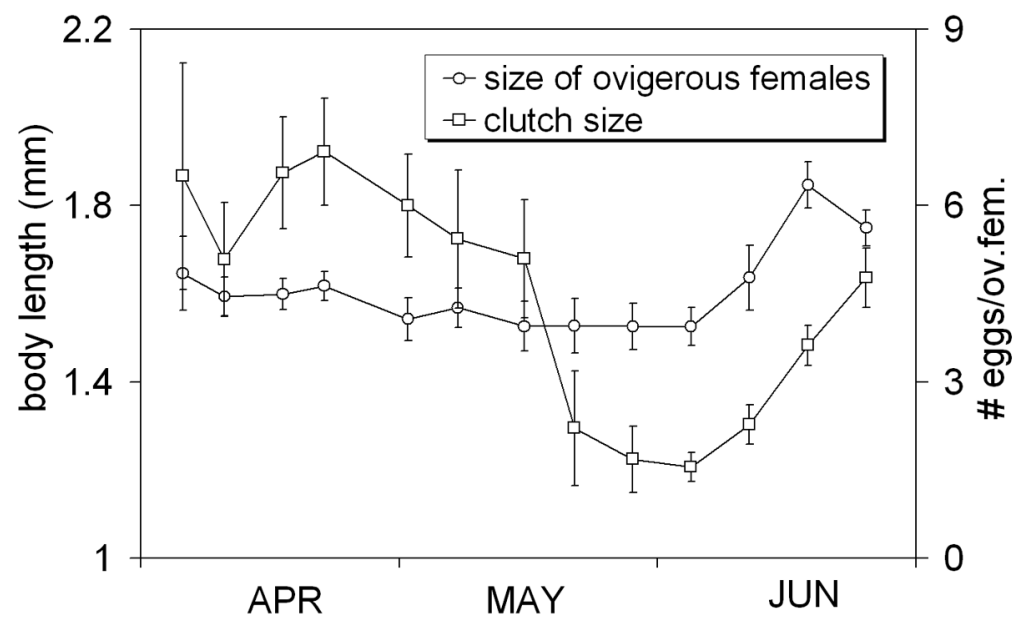

Fig. 3. Seasonal changes in size of Daphnia ovigerous females and in the clutch size (mean $\pm 1.96 \mathrm{SE})$.

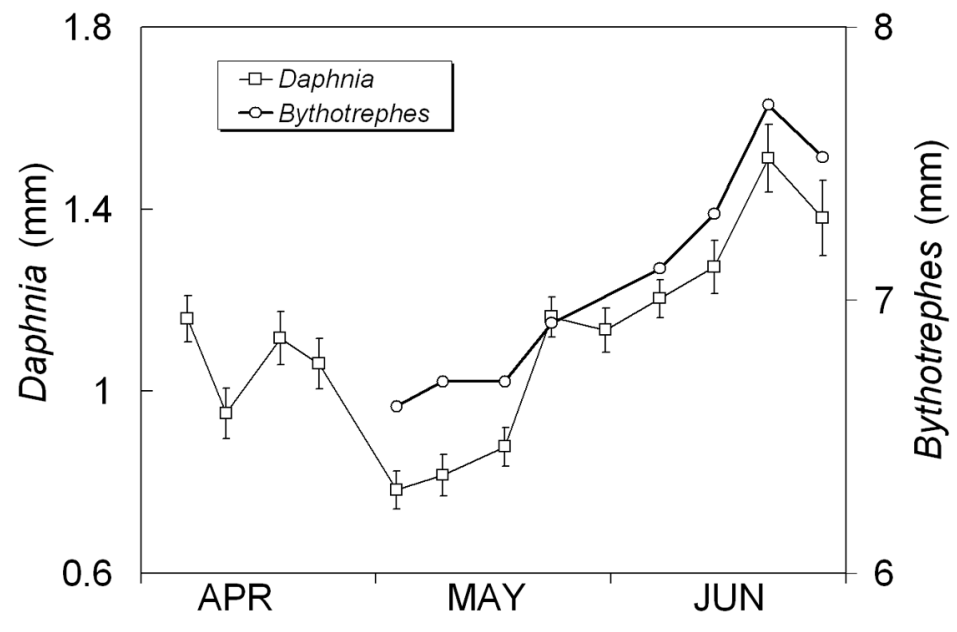

Fig. 4. Seasonal changes in Daphnia mean $( \pm 1.96 \mathrm{SE})$ body size, along with Bythotrephes maximum body size.

se fish typically produce a stronger effect on the size structure than on fecundity of their prey. When invertebrate predation prevails, changes in Daphnia birth rate are also determined by $C o n A$ and $C o n F$, but now the ConA-ConF pattern is expected to be more uniform. This is because the effects produced by invertebrates are apparently weaker than those by fish, and weak effects are perceived as less variable.

During April-mid May, contribution analysis revealed a ConA-ConF pattern that is expected under fish predation. Moreover, the selective removal of larger ovigerous females expected on the basis of the contributions, was accompanied by a decrease in Daphnia body size (maximum and mean body size, as well as the mean size of ovigerous females) and a reduced mean clutch size observed in the lake. This pattern typically occurs in
Lago Maggiore during April-mid May, when Daphnia is the preferred prey of coregonid fish (Giussani 1974; Volta 2000).

During mid May-June, contribution analysis revealed that changes in Daphnia birth rate also resulted from both ConA and ConF, but the difference between these contributions was less pronounced than that observed in the previous period. This is what we expect under invertebrate predation. In addition, not only did Daphnia mean body size increase but also the mean size of the ovigerous females remained almost constant, which can be explained by the prevailing removal of small immature individuals. In the second half of June the mean size of ovigerous females started to increase, which indicates that also small ovigerous females were removed. This shows that invertebrate predators, most probably 


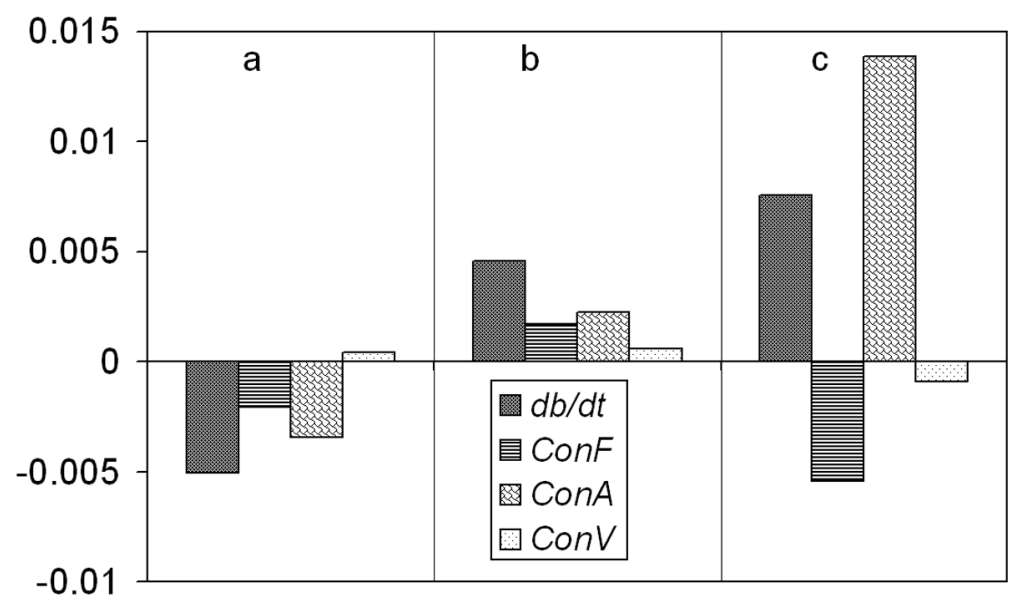

Fig. 5. Contributions of $F, A$ and $V(C o n F, C o n A, C o n V)$ to changes in Daphnia birth rate $(d b / d t)$ in time intervals from periods representative of predation by $a$ ) zooplanktivorous fish (early April); b) Bythotrephes longimanus (early May); c) Leptodora kindtii (late June). $V$ is egg developmental rate $\left(\right.$ day $\left.^{-1}\right), F$ is fecundity, the ratio of eggs numbers to adult females numbers (irrespective of whether those females carry eggs or not), and $A$ is the proportion of adult females to the total number of individuals in the population.

Bythotrephes, which was in terms of biomass the most abundant one, were the dominant predators on Daphnia. Changes in Daphnia body size and the relative contributions of population traits to changes in birth rate can be explained by viewing Bythotrephes as a predator able to select not only young, but also some of the small sized ovigerous Daphnia, in parallel with the increase in predator body size. Although Bythotrephes predation seems to produce similar effects on Daphnia population dynamics as fish predation, affecting both fecundity and the proportion of adults, it can be distinguished in two ways from fish predation. Firstly, by an increase in Daphnia mean body size, whereas the mean size of ovigerous females remains approximately constant (mid May-mid June) or increased in size (mid June-end of June). Secondly, because the pattern of contributions to Daphnia birth rate dynamics observed under the implied Bythotrephes predation is more uniform than that observed under implied fish predation.

During late June, contribution analysis revealed that changes in Daphnia birth rate were determined by ConA, a pattern in that respect somewhat similar to that observed in April (see Fig. 5). It can be hardly attributed to fish pressures however, because at that time the dominant predator in the lake was Leptodora rather than fish. On the other hand, it can be hardly indicative of invertebrate pressures because for invertebrates we expect a more uniform ConA-ConF pattern, a sort of that shown in Fig. 5b. Apparently, contribution results do not reflect the pressures by Leptodora at that time, because the density of Daphnia was extremely low in late June (Fig. 1) and Leptodora might switch to another food source.

We conclude that both predation by zooplanktivorous fish and by invertebrate predators are affecting popula- tion dynamics of Daphnia in Lago Maggiore. Among the invertebrate predators Bythotrephes has the largest impact on Daphnia dynamics, both because its relatively high population biomass and its relatively large body size. In the second half of June its size is large enough to predate also on small ovigerous Daphnia, and its predation pressure is high enough to reduce the Daphnia densities to low values.

\section{ACKNOWLEDGEMENTS}

We wish to thank P. L. Starkweather for suggestions and the critical review of the manuscript. Comments by two anonymous reviewers substantially improved the original version of the manuscript. This study was carried out within the research activity of M. Manca on zooplankton of Lago Maggiore ("Population dynamics of zooplanctonic Cladocera of Lago Maggiore in relation to environmental variables", year 2004), funded by CNR to M. Manca. L. V. Polishchuk was partially supported by grant 07-04-00521 from the Russian Foundation for Basic Research. J. Vijverberg was supported by a CNR Short-Mobility grant in 2006 .

\section{REFERENCES}

Arndt, H., M. Krocker, B. Nixdorf \& A. Köhler. 1993. Long term annual and seasonal changes of metazooplankton in Lake Müggelsee (Berlin): effects of eutrophication, grazing activities and the impact of predation. Int. Revue ges. Hydrobiol., 78: 379-402.

Barbiero, R.P. \& M.L. Tuchman. 2004. Changes in the crustacean communities of Lakes Michigan, Huron, and Erie following the invasion of the predatory cladoceran Bythotrephes longimanus. Can. J. Fish. Aquat. Sciences, 61: 2111-2125. 
Boudreau, S.A. \& N.D. Yan. 2003. The differing crustacean zooplankton communities of Canadian Shield lakes with and without the nonindigenous zooplankktivore Bythotrephes longimanus. Can. J. Fish. Aquat. Sciences, 60: 1307-1313.

Branstrator, D.K. 1998. Predicting diet composition from body length in the zooplankton predator Leptodora kindti. Limnol. Oceanogr., 43: 530-535.

Branstrator, D. K. \& J.T. Lehman. 1991. Invertebrate predation in Lake Michigan regulation of Bosmina longirostris by Leptodora kindtii. Limnol. Oceanogr., 36: 483-495.

Browman, H. I., S. Kruse \& W.J. O‘Brien. 1989. Foraging behavior of the predaceous cladoceran, Leptodora kindtii, and escape responses of their prey. J. Plankton Res., 11: 1075-1088.

Caswell, H. 1989. Analysis of life table response experiments. I. Decomposition of effects on population growth rate. Ecol. Model., 46: 221-237.

de Bernardi, R. 1974. The dynamics of a population of Daphnia hyalina Leydig in Lago Maggiore, Northern Italy. Mem. Ist. ital. Idrobiol., 31: 221- 243.

de Bernardi, R., G. Giussani \& M. Manca. 1987. Cladocera: predators and prey. Hydrobiologia, 145: 225-243.

Edmondson, W.T. 1968. A graphical model for evaluating the use of the egg ratio for measuring birth and death rates. Oecologia, 1: 1-37.

Gerritsen, J. \& J.R. Strickler. 1977. Encounter probabilities and community structure in zooplankton: a mathematical model. Can. J. Fish. Aquat. Sciences, 34: 73-82.

Giussani, G. 1974. Planctofagia selettiva del coregone bondella (Coregonus sp.) del Lago Maggiore. Mem. Ist. ital. Idrobiol., 31: 181-203.

Gliwicz, Z. M. \& J. Pijanovska. 1989. The role of predation in zooplankton succession. In: U. Sommer (Ed.) Plankton Ecology: Succession in plankton communities. Springer: 253-296.

Herzig, A. 1994. Predator-prey relationships within the pelagic community of Neusiedlersee. Hydrobiologia, 276: 81-96.

Herzig, A. 1995. Leptodora kindtii: efficient predator and preferred prey item in Neusiedler See, Austria. Hydrobiologia, 307: 273-282.

Lunte, C. C. \& C. Luecke. 1990. Trophic interactions of Leptodora in Lake Mendota. Limnol. Oceanogr., 35: 10911100.

Manca, M. M., A. Calderoni \& R. Mosello. 1992. Limnological research in Lago Maggiore: studies on hydrochemistry and plankton. Mem. Ist. ital. Idrobiol., 50: 171-200.

Manca, M. \& P. Comoli. 1995. Seasonal-changes in size of the feeding basket of Leptodora kindtii (Focke) in LagoMaggiore as related to variations in prey size selection. Limnol. Oceanogr., 40: 834-838.

Manca, M. \& D. Ruggiu. 1998. Consequences of pelagic foodweb changes during a long-term oligotrophication process. Limnol. Oceanogr., 43: 1368-1373.
Manca, M., C. Ramoni \& P. Comoli. 2000. The decline of Daphnia hyalina galeata in Lago Maggiore: A comparison of the population dynamics before and after oligotrophication. Aquat. Sci., 62: 142-153.

Manca, M., M. Portogallo \& M.E. Brown. 2007. Shifts in phenology of Bythotrephes longimanus and its modern success in Lake Maggiore as a result of changes in climate and trophy. J. Plankton Res., 29: 515-525.

Martin, J.W. \& C.E. Cash-Clark. 1995. The external morphology of the onychopod 'cladoceran' genus Bythotrephes (Crustacea, Branchiopoda, Onychopoda, Cercopagididae), with notes on the morphology and phylogeny of the order Onychopoda. Zoologica Scripta, 24: 61-90.

Paloheimo, J.E., 1974. Calculation of instantaneous birth rate. Limnol. Oceanogr., 19: 692-694.

Polishchuk, L.V. 1995. Direct positive effect of invertebrate predators on birth rate in Daphnia studied with a new method of birth rate analysis. Limnol. Oceanogr., 40: 483489.

Polishchuk, L.V. 1999. Contribution analysis of disturbancecaused changes in phytoplankton diversity. Ecology, 80: 721-725.

Polishchuk, L.V. \& J. Vijverberg. 2005. Contribution analysis of body mass dynamics in Daphnia. Oecologia, 144: 268277.

Schulz, K.L. \& P.M. Yurista. 1999. Implications of an invertebrate predator's (Bythotrephes cederstroemi) atypical effects on a pelagic community. Hydrobiologia, 380: 179-193.

Strecker, A.E., S.E. Arnott, N.D. Yan \& R. Girard. 2006. Variation in the response of crustacean zooplankton species richness and composition to the invasive predator Bythotrephes longimanus. Can. J. Fish. Aquat. Sci., 63: 2126-2136.

Vanderploeg, H. A., J.R. Liebig \& M. Omair. 1993. Dynamics of the Bythotrephes invasion of the St. Lawrence Great Lakes. J. Great Lakes Res., 16: 346-351.

Volta, P. 2000. Il regime alimentare delle diverse forme di coregone (Coregonus spp.) del Lago Maggiore alla luce della recente evoluzione trofica ambientale. Master Thesis, Tesi laurea, facoltà di Science Biologiche, Università delll'Insubria, Varese.

Yan, N.D., A. Blukacz, W.G. Sprules, P.K. Kindy, D. Hackett, Girard, R.E. \& B.J. Clarck. 2001. Changes in the zooplankton and the phenology of the spiny water flea, Bythotrephes, following its invasion of Harp Lake, Ontario, Canada. Can. J. Fish. Aquat. Sciences, 58: 2341-2350.

Yan, N. D., R. Girard \& S. Boudreau. 2002. An introduced invertebrate predator (Bythotrephes) reduces zooplankton species richness. Ecol. Lett., 5: 481-485.

Zaret, T.M. 1980. Predations and freshwater Communities. New Haven and London Yale University Press: 187 pp. 